\title{
Study on the Impact of Production Agglomeration of China's Aquatic Products on Export Competitiveness
}

\author{
Weiwei $\mathrm{Fu}^{1,2}$, Peifen Zhuang ${ }^{{ }^{*}}$ \\ ${ }^{1}$ College of Economics and Management, Fujian Agriculture and Forestry University, China \\ ${ }^{2}$ College of Computer and Information Sciences, Fujian Agriculture and Forestry University, China
}

\begin{abstract}
This paper collects the data of China's aquatic products from 2002 to 2018 and studies the relationship between the production agglomeration and export competitiveness of aquatic products. This paper calculates the production Concentration Rate (CR) which reflects the degree of agglomeration of aquatic products and the Revealed Comparative Advantage (RCA) index which reflects the export competitiveness of aquatic products, and then uses variable intercept model with fixed effects to empirically analyze the impact of production agglomeration of three main aquatic products (fish, crustacean and shellfish) on the export competitiveness. The results show that there is an obvious phenomenon of production agglomeration of aquatic products in China. Overall, the improvement of production agglomeration of aquatic products is conducive to the promotion of export competitiveness.
\end{abstract}

\section{Introduction}

With the continuous refinement of industrial division and the development of economic globalization, production agglomeration has become an important form of regional industrial organization and a fundamental way for a country to improve its export competitiveness. The classical theories of industrial agglomeration and export competitiveness were mainly embodied in the local market effect of New Economic Geography [1] and Porter's national competitive advantage theory with industrial clusters and national competitiveness as the main research object. China's domestic empirical research on manufacturing industry agreed that industrial agglomeration could increase exports or improve export competitiveness [2].

With the development of agriculture in China, the degree of agglomeration of agricultural production is also increasing. Is the agglomeration of agricultural production also conducive to agricultural exports competitiveness? Zepponi et al. (2007) pointed out that the agglomeration of agricultural industry could improve the level of agricultural specialization and the international competitiveness of regional industries [3]. Tveteras et al. (2006) considered that the agglomeration of fishery could promote productivity effectively [4]. Zhang Hongsheng (2007) analyzed the effect of industrial agglomeration on improving agricultural competitiveness from the perspective of mechanism, which was mainly reflected in the promotion of four aspects of efficiency, namely transaction efficiency, production efficiency, competition efficiency and innovation efficiency [5]. In terms of fruit industry, the results of Xiang Yun et al.
(2014) showed that, there was a significant positive correlation between geographical agglomeration of fruit industry and international competitiveness [6]. Cheng Xiaoping (2014) argued that industry agglomeration was positively correlated with the competitiveness of dairy products industry [7]. Tian Suyan et al. (2012) used VAR model to conduct empirical research of aquatic products, and the results showed that the agglomeration of China's aquatic industry has negative transmission on industrial competitiveness and positive transmission on enterprise competitiveness [8].

Under the influence of trade structure adjustment and international trade barriers, the competitiveness of China's aquatic products trade has declined [9]. In the study of factors affecting the export competitiveness of aquatic products, Cai Xin et al. (2018) used the Revealed Comparative Advantage index to measure the export competitive advantage of China's aquatic products, and found that the resource endowment, economic scale, demand for aquatic products and economic system in China and trading partner all had significant effects on the competitiveness of China's aquatic products [10]. Zheng Sining et al. (2019) used international market share, Revealed Comparative Advantage index and Trade Competitiveness index to measure the international competitiveness of aquatic products in Fujian and Taiwan, and indicated that the promotion effect of related and supporting industries was the most, and the shortage of human capital became the key to hinder fishery international competitiveness [11]. Shao Guilan et al. (2020) thought that the main factors influencing the international competitiveness of marine fisheries were

\footnotetext{
* Corresponding author: pfzhuang@hotmail.com
} 
infrastructure, disposable income of urban residents per capita, labor force and technology [12].

Aquatic products account for the largest proportion of China's export of agricultural products and the export volume is also increasing year by year. But it was found that the export competitiveness of aquatic products fluctuated in recent years. At present, there is a lack of research on the impact of the production agglomeration of different aquatic products on export competitiveness. Therefore, on the premise of fully ensuring the domestic effective supply, from the perspective of comparative advantage, this paper studies the relationship between production agglomeration of aquatic products and its export competitiveness, and tries to find out the effective ways to improve the export competitiveness, so as to promote the healthy development of aquatic products industry which plays an important role in reality.

\section{Situation of production agglomeration and export competitiveness of China's aquatic products}

\subsection{Data sources}

In this paper, fish, crustaceans and shellfish are selected as the main research objects. According to China National Bureau of Statistics, fishery is divided into five categories: fish, crustaceans, shellfish, algae, and others. According to the statistics department of the United Nations and China Customs, fishery is mainly classified as HS: 03-fish and other aquatic invertebrates, while algae is classified as food. In order to avoid ambiguity, algae and other species are excluded, and only fish, crustaceans and shellfish are analyzed in the research. The production of these three species has accounted for more than $80 \%$ of aquatic products in China, which is representative enough. The data of import and export volume of three kinds of aquatic products and China's total export volume come from the statistics department of the United Nations and China Customs. The data of total export volume of aquatic products of the world come from China's Foreign Trade and Economic Statistics Yearbook, and the output data come from China's Fishery Statistics Yearbook. Due to the great changes in foreign trade after China joined WTO in 2002, the study period is from 2002 to 2018 to ensure comparability.

\subsection{Analysis on production agglomeration of China's aquatic products}

The Concentration Rate (CR) is used to measure the degree of concentration of aquatic products, and the formula is as follows:

$$
C R_{m}=\sum_{i=1}^{m} c_{i} \times 100 \%
$$

In the formula, $m$ is the number of regions and 5 is selected in the paper. ${ }^{c}{ }_{i}$ represents the output of a certain aquatic product in a region accounts for the proportion of the output of that aquatic product in the whole country.
The higher the $\mathrm{CR}$ is, the higher the concentration degree is.

The CR of total aquatic products and three main China's aquatic products is shown in Figure 1. Generally speaking, the degree of production agglomeration of aquatic products in China was relatively high, and the CR was $56.57 \%$ during the study period, but the values showed a trend of continuous decline then a small increase. We found that the degrees of production agglomeration of shellfish and crustacean were high and more than $60 \%$. The average CR of crustaceans was $66.62 \%$, and that of shellfish was more than $80 \%$. The fluctuation of these two kinds of aquatic products was relatively small, but the overall production concentration rate was high and stable.

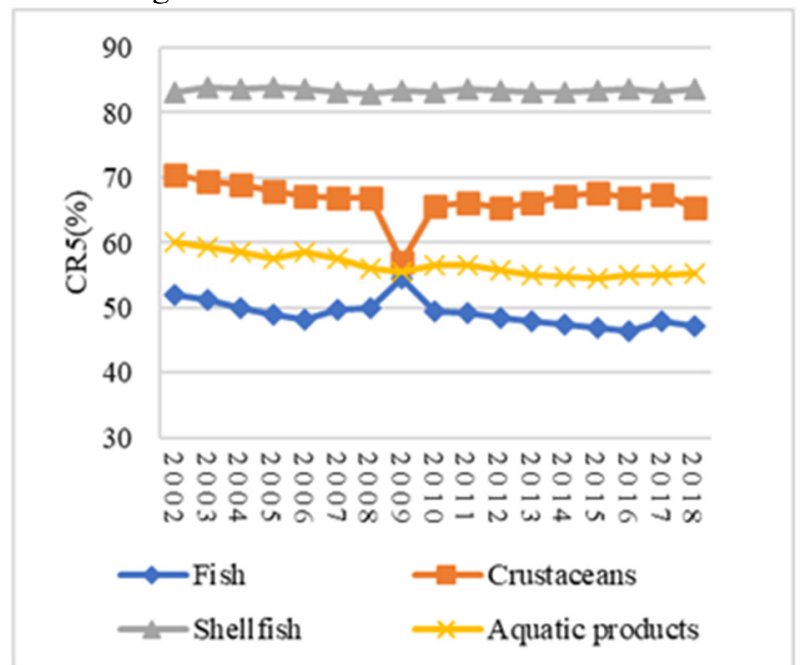

Fig 1. Concentration rate of China's aquatic products from 2002 to 2018

\subsection{Analysis on export competitiveness of China's aquatic products}

Revealed Comparative Advantage (RCA) index is used to analyze the export competitiveness of aquatic products, and the formula is:

$$
R C A_{\mathrm{ij}}=\frac{X_{i j} / X_{i t}}{X_{w j} / X_{w t}}
$$

In the formula, ${ }^{X_{\mathrm{ij}}}$ refers to the export value of China's aquatic products, $X_{\text {it }}$ refers to the total export value of all China's products, ${ }^{X_{\mathrm{wj}}}$ refers to the total export value of the world's aquatic products, and $X_{\mathrm{wt}}$ refers to the total export value of all the world's products. The larger the RCA is, the stronger its export competitiveness is.

The results of RCA are shown in Figure 2. The RCA of China's aquatic products was greater than 1 in most years of the study period with an average value of 1.1152 , and the export volume was also increasing year by year. Overall, China's aquatic products trade still had a certain competitive advantage. The peak of RCA in 2010 may be due to the impact of financial crisis on the supply of international aquatic products market. It showed a small downward trend after a few years. Because of the tightening of aquatic product resources, the reduction of available breeding space, and the continuous 
improvement of production costs, the growth rate of aquatic products decreased significantly since 2017, the $\mathrm{RCA}$ began to be lower than 1 at the same time.

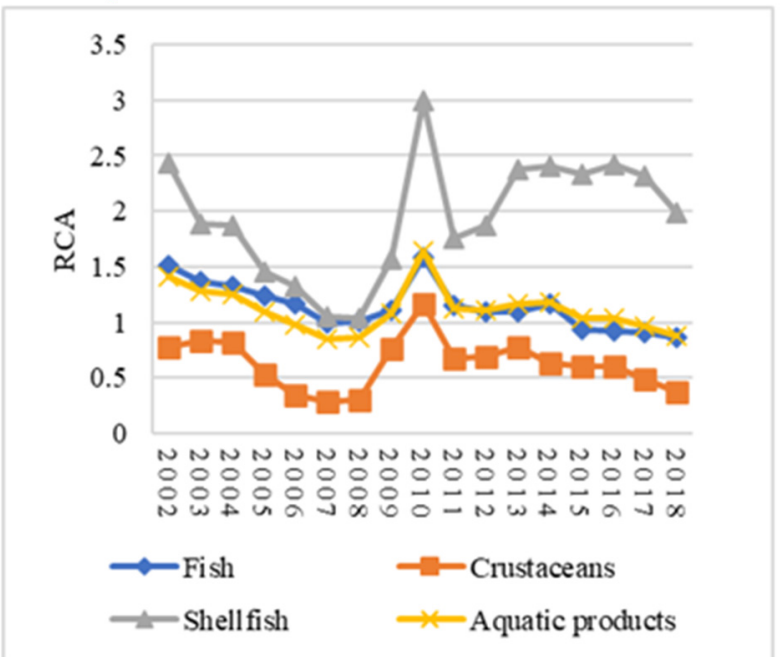

Fig 2. Revealed comparative advantage index of China's aquatic products from 2002 to 2018

From the perspective of species, fish and shellfish have a strong comparative advantage. The average RCA of fish was 1.1459 and more than 1 in most years. However, the RCA of fish began to be lower than 1 and showed a downward trend since 2015 . The average RCA of shellfish was 1.9460, and its value fluctuated around 2 . The average RCA of crustaceans was 0.629241 which was lack of advantages, only greater than 1 in 2010 and less than 1 in other years.

\section{Results}

It can be seen from the above analysis that the export data of China's aquatic products in 2010 may be abnormal due to the impact of economic crisis. Therefore, this part excludes the data of 2010 and establishes a panel model of production agglomeration and export competitiveness based on the data of fish, crustaceans and shellfish in other years. The equation is as follows:

$$
\ln R C A_{i t}=\alpha_{i t}+\beta_{i t} \ln C R_{i t}+\mu_{i t}
$$

In the equation, $R C A_{i t}$ measures the export competitiveness of aquatic products, $C R_{i t}$ measures the degree of production agglomeration of aquatic products, $\alpha_{i t}$ represents the constant term or intercept term of the model, and $\beta_{i t}$ is the coefficient of $C R_{i t}$. The logarithm of $R C A_{i t}$ and $C R_{i t}$ is taken to avoid pseudo regression. After the unit root test, the two series are $\mathrm{I}(0)$ stationary series and there is a co-integration relationship, so we can establish a panel data model.

First, F-test is used to determine whether to build variable coefficient or intercept panel data model with fixed effects. The two hypotheses of the test are: $H_{1}: \beta_{1}=\beta_{2}=\cdots=\beta_{N}$ (same coefficient, different intercept), $H_{2}: \beta_{1}=\beta_{2}=\cdots \beta_{N}, \alpha_{1}=\alpha_{2}=\cdots=\alpha_{N}$ (same coefficient, same intercept).
Under the assumption of $\mathrm{H}_{2}$, the test statistic $\mathrm{F}_{2}$ follows F-distribution.

$$
F_{2}=\frac{\left(\mathrm{S}_{3}-\mathrm{S}_{1}\right) /(N-1)(k+1)}{S_{1} /[N T-N(k+1)]} \sim F[(N-1)(k+1), N(T-k-1)]
$$

If $\mathrm{H}_{2}$ is rejected, then we suppose $\mathrm{H}_{1}$. The test statistic $\mathrm{F}_{1}$ also follows $\mathrm{F}$-distribution.

$$
F_{1}=\frac{\left(\mathrm{S}_{2}-\mathrm{S}_{1}\right) / k(N-1)}{S_{1} /[N T-N(k+1)]} \sim F[k(N-1), N(T-k-1)]
$$

$N$ is the sample size, $k$ is the number of explanatory variables, $S_{l}$ represents the sum of squares of the residuals of variable coefficient model with fixed effects, $S_{2}$ represents the sum of squares of the residuals of the variable intercept model with fixed effects, and $S_{3}$ represents the sum of squares of the residuals of the mixed model.

By calculating the sum of squares of residuals of the above three models, we can get: $S_{1}=3.4196, S_{2}=3.5267$, $S_{3}=13.2550$. Because $n=3, k=1, t=17, F_{2}=32.35707>$ $F_{0.05}(4,45)=2.5787, H_{2}$ is rejected and then $H_{l}$ is tested. For $F_{l}=0.7047<F_{0.05}(2,45)=3.2043$, we fail to reject $H_{l}$ so variable intercept model with fixed effects is chosen.

In this paper, the Generalized Least Squares (GLS) method is used to estimate the model with the variance of the cross-sectional model residuals as the weight, and variable intercept panel data model with fixed effects which $\operatorname{lnRCA}$ is the dependent variable and $\operatorname{lnCR}$ is the independent variable is established. The results of model estimation are shown in Table 1. In the model, $R^{2}=0.7112, R_{a}^{2}=0.6915, F=36.1128, D W=0.7187$

Table1. The results of the model.

\begin{tabular}{|c|c|c|c|}
\hline Variables & Coefficient & t-Statistic & Prob \\
\hline Constant & 0.8009 & 2.4231 & 0.0196 \\
\hline $\operatorname{lnCR}$ & 1.7545 & 2.3080 & 0.0258 \\
\hline
\end{tabular}

The results of $\alpha_{i}$ are shown in Table 2. The model fits well. The equation of the model is:

$\ln R C A_{i t}=0.8009+\alpha_{i}+1.7545 \ln C R_{i t}$
\begin{tabular}{|c|c|}
$\begin{array}{c}\text { Table2. } \\
\begin{array}{c}\text { Fixed } \\
\text { effects }\end{array}\end{array}$ & Coefficient \\
\hline Fish & 0.5485 \\
\hline Crustaceans & -0.6613 \\
\hline Shellfish & 0.1128 \\
\hline
\end{tabular}

From the empirical results, we can draw that there is a significant positive correlation between the overall production agglomeration and export competitiveness of China's aquatic products. The coefficient of $\operatorname{lnCR}$ in the equation is positive, and it is significant at the significance level of $5 \%$. The coefficient can be regarded as the promotion degree of export competitiveness, so the contribution of production agglomeration of aquatic 
products to its export competitiveness is 1.7545 . In other words, the export competitiveness of aquatic products will increase by $1.7545 \%$ when the degree of production agglomeration increases by $1 \%$.

\section{Conclusions}

By collecting the relevant data of China's aquatic products from 2002 to 2018, this paper estimates the degree of production agglomeration and export competitiveness of China's aquatic products, and constructs variable intercept panel data model with fixed effects to make an empirical study on the relationship between them. The main conclusions are as follows:

(1) The degree of production agglomeration of China's aquatic products is relatively high and stable, and the export competitiveness of distinct aquatic products is different. Shellfish has the highest concentration rate, followed by crustaceans, and fish has the lowest rate. In general, China's aquatic products have certain competitive advantages, while shellfish products have obvious competitive advantages, fish products have certain but not obvious competitive advantages, and crustaceans have no competitive advantages. Relative to the degree of production agglomeration, the export competitiveness presents the stage characteristics of first declining, then rising, and slowly declining at last.

(2) There is a positive correlation between production agglomeration and export competitiveness of China's aquatic products. Through the results of the empirical model, it is proved that the higher the degree of agglomeration of aquatic products, the more conducive to the improvement of export competitiveness of aquatic products on the whole. The scale effect of industrial agglomeration reduces the production cost and raises the productivity, so as to improve the export competitiveness, which in turn promotes the productivity, thus forming a virtuous circle effect of industrial agglomeration. Therefore, the government can actively respond to the changes in the international aquatic products market, combine with the local aquatic products situation, introduce corresponding policies to ensure and enhance the regional production capacity. At the same time, by means of regulation and control, the production chain can be concentrated in one area, so the production line can be improved, and the industrial agglomeration can be accelerated. We should encourage small and mediumsized enterprises to strengthen production agglomeration, and support the behaviors which help to the agglomeration of aquatic products.

\section{Acknowledgment}

This research was funded by the Science and Technology Innovation Project of Fujian Agricultural and Forestry University (No. CXZX2020008) and Fujian Education and Scientific Research Program for young and middleaged teachers (No. JAT190141).

\section{References}

1. Krugman P.R. (1980) Scale economies, product differentiation, and the pattern of trade. American Economic Review, 70: 950-959.

2. Xie Z.Y., Ju F.H. (2014) Homogeneous agglomeration, heterogeneous agglomeration and industrial international competitiveness: An empirical study based on panel data of 15 manufacturing industries in China from 2000 to 2011. International Trade Issues, 2: 13-23.

3. Zepponi D., Fisch R. (2007) Industry-driven leadership is vital for rural communities. Economic Development America, 12: 20-23.

4. Tveteras R., Battese G.E. (2006) Agglomeration externalities, productivity, and technical inefficiency. Journal of Regional Science, 4: 605625.

5. Zhang H.S. (2007) Research on China's Agricultural Industrial Agglomeration. China Agricultural Publishing, Beijing.

6. Xiang Y., Wang W.X., Qi C.Q. (2014) The correlation between geographical agglomeration and agricultural international competitiveness: evidence from China's fruit industry. Guangdong Agricultural Sciences, 13: 202-207, 240.

7. Cheng X.P. (2014) Spatial Agglomeration of China's Dairy Industry: Theoretical and Empirical Analysis. China University of Political Science and Law Press, Beijing.

8. Tian S.Y., Zhou L., Zhang Q. (2012) Research on industrial agglomeration and export competitiveness of China's aquatic products generalized pulse analysis based on VAR model. Jiangsu Agricultural Science, 40: 374-377.

9. Wang J.D., Jiang K.J., Wang J., et al. (2019) Evaluation on international trade pattern and competitiveness of China's aquatic products. China's Fishery Economy, 37: 49-58.

10. Cai X., Chen Y.F., Chen J. (2018). Empirical analysis on influencing factors of international competitiveness of aquatic products in China. Journal of Dalian University of Technology (Social Science Edition), 39: 47-54.

11. Zheng S.N., Wang S.Q., Zheng Y.F. (2019) A comparative study on the international competitiveness of fisheries between Fujian and Taiwan and its influencing factors - the policy choice of fisheries cooperation between Fujian and Taiwan in the context of free trade zone. Journal of China Agricultural University (Social Science Edition), 24: 237-250.

12. Shao G.L., Dong X.R. (2020) Research on influencing factors of international competitiveness of China's marine fishery. China's Fishery Economy, 38: 72-83. 